\section{JUICIOS MORALES Y FRONTERAS BIOLÓGICAS: MÁS ALLÁ DE LA FRONTERA RAZÓN/ EMOCIÓN}

\author{
Mar Cabezas \\ Facultad de Filosofía. Universidad de Salamanca \\ marcabezas@usal.es
}

Cómo citar este artículo/ Citation: Cabezas, M. (2013). "Juicios morales y fronteras biológicas: más allá de la frontera razón/emoción". Arbor, 189 (762): a052. doi: http://dx.doi. org/10.3989/arbor.2013.762n4003

Recibido: 13 julio 2012. Aceptado: 6 junio 2013.

RESUMEN: Construimos fronteras con supuesta base biológica y derivamos juicios morales de ellas. Asimismo, suponemos que fueron nuestras emociones - el miedo, el asco o la rabia - las que nos llevaron a tal error, especialmente cuando nos damos cuenta de la inconsistencia lógica de derivar juicios morales de dichas fronteras. En consecuencia, solemos identificar emociones con prejuicios, creencias u opciones falaces de las que más nos valdría librarnos.

Sin embargo, como se tratará de argumentar a continuación, las emociones no son la causa del problema. Primero, porque el marco conceptual clásico dicotómico en el que razón y emoción son dos polos opuestos regidos por una tensión irreconciliable es a su vez cuestionable. Segundo, porque las emociones, en cuanto alarmas transmisoras de información relevante, pueden ser un elemento tremendamente útil en la identificación y superación de las discriminaciones surgidas de las fronteras dicotómicas. Así, el objetivo de este trabajo es analizar la relación de estos tres elementos, a saber, fronteras biológicas, juicios morales y emociones $y$, finalmente, argumentar a favor de las conexiones entre razón y emoción, mostrando los posibles beneficios de remplazar el modelo dualista por uno relacional.

PALABRAS CLAVE: fronteras biológicas; juicios morales; razón; emoción; dicotomía; moral.

\section{MORAL JUDGEMENTS AND BIOLOGICAL BOUNDARIES: BEYOND THE REASON/ EMOTION BOUNDARY}

Copyright: (C) 2013 CSIC. Este es un artículo de acceso abierto distribuido bajo los términos de la licencia Creative Commons Attribution-Non Commercial (by-nc) Spain 3.0.

ABSTRACT: We build boundaries that are theoretically based on biological grounds and we derive moral judgments from them. Likewise, we take for granted that emotions such as fear, disgust or rage were the element that led us to this mistake, especially when we realise the logical inconsistency of deriving moral judgments in this way. Consequently, we often associate emotions with prejudices, beliefs or fallacies, which we ought to free ourselves from.

However, emotions are not the cause of the problem. Firstly, because the classical dichotomical framework that defends the reason/emotion polarity is also questionable. Secondly, because emotions, as alarms which transmit important information, may be a key element in the discovery and overcoming of the discriminations that arise at the boundaries of dichotomies. Thus, the aim here is to analyse the relationship between these three elements: biological boundaries, moral judgments and emotions. And then toargue in favour of the links between reason and emotions as a way of surpassing the old dichotomic model, and, to conclude, I will point out some of the benefits of replacing a dualistic framework by an interactive one.

KEYWORDS: biological boundaries; moral judgments; reason; emotion; dichotomy; morality. 


\section{1. ¿QUÉ SON LAS FRONTERAS BIOLÓGICAS?}

La filosofía moral ha estado dominada en su tratamiento de problemas prácticos, tanto en el pasado como en el presente, por clasificaciones morales de base supuestamente ontológica/biológica, a saber, las fronteras biológicas.

Asimismo, es fácilmente constatable que, aún hoy, se construyen fronteras basadas en diferencias biológicas en multitud de casos. Quizás las más relevantes o visibles sean las de la especie, el sexo, la etnia e incluso la cultura en los casos en los que es comprendida como un organismo vivo que funciona como una unidad al margen de las demás. Del mismo modo, se encuentran fronteras al inicio y al final de la vida, entre lo natural y lo artificial, entre lo humano y lo no humano, etc.

Igualmente, estas conceptualizaciones de lo real se mueven en una lógica dual $-p$. ej. humano/animal, hombre/mujer, cultura/naturaleza, razón/emoción-, dicotómica, valorativa, jerarquizante y sobre todo excluyente al subordinar una de las dos caras de la disyunción a la otra. En este sentido, como fronteras valorativas, no son sino formas de discriminar. Efectivamente, dado que implican una valoración de lo real respecto del esquema dual previo, influyen en el tratamiento de los problemas morales y legales.

Dicho de otro modo, y siguiendo las tesis de K. J. Warren (1990), la construcción de las fronteras biológicas asume un marco conceptual dualista y dicotómico, basado en una tensión irreconciliable entre ambas partes de todo, en el que uno de los polos se convierte en el término privilegiado (A) frente al defectuoso (no-A), y en el que la subordinación se justifica como moralmente inherente a la relación entre $A$ y no-A.

En este sentido, se puede afirmar que las fronteras biológicas se asientan en una estructura argumentativa dicotómica identificada por distintas autoras como la "mentalidad del muro de Berlín" (Prokhovnik, 1999, 21), la "lógica de dominación" (Warren, 1990, 127) o la "lógica de la colonización" (Plumwood, 1993, 41).

Al mismo tiempo, las fronteras biológicas son, pues, construcciones humanas cuyo fin principal es clasificar y sistematizar la viscosa y escurridiza complejidad de la realidad.

No obstante, que sean construcciones humanas no implica negar la existencia de diferencias biológicas en las que se asientan las mismas, ni siquiera implica en- trar en el grado de realidad biológica u ontológica de tales diferencias.

Por el contrario, simplemente supone llamar la atención sobre dos ideas a veces entremezcladas, a saber, 1) que del grado de realidad biológica de las diferencias no se deriva necesariamente el mismo grado de realidad biológica de las fronteras y, 2) que la realidad es un continuo, una amalgama de procesos y relaciones, siendo el ser humano el que analiza, clasifica y pone límites. Dicho de un modo más simple, vemos las diferencias, pero no las fronteras.

Incluso si se pensase que no son construidas por el ser humano y que existen de hecho, esto solo demostraría que son naturales, pero no "morales," por lo que, en un sentido estricto, no encerrarían ningún juicio de valor en sí y por sí mismas.

Por tanto, se parta de la cosmovisión que se parta, más o menos naturalista o constructivista, se podría admitir que las fronteras son construcciones, pues encontrar en la realidad una diferencia entre $A$ y no- $A$ no implica encontrar en la realidad una frontera entre ellas. En palabras de S. Pinker, "algunas distinciones (...) pueden tener algún grado de realidad biológica, aunque no sean unas fronteras exactas entre unas categorías fijas" (Pinker, 2003, 219).

Estas clasificaciones se pueden construir de diversas maneras, como de hecho ya ha ocurrido: bien por eliminación, prescindiendo o ignorando aquello que complicaría la misma, ya sea por conocimiento o por desconocimiento, bien por asimilación, interpretando lo desconocido según los patrones de nuestra clasificación con el fin de que encaje en esta (Charo, 1999, 277-292).

En suma, las fronteras biológicas son formas de clasificar, ordenar y simplificar la realidad que afectan a tres dimensiones vitales para el ser humano: la ontológica (ser), la epistemológica (saber) y la moral (hacer). Canalizan la información sobre nuestra identidad, sobre el mundo, y sobre nuestros actos. Así, son un modo de acercamiento a la realidad mediante el que construir la propia identidad en relación a "lo otro," lo que no se es. Son una manera simple de conocer lo que quizás sea más complejo y son límites de lo normal, pues tanto la frontera en sí misma como todo lo que cae dentro de ella se mueve en el eje de lo conocido, convirtiéndose finalmente en criterio de acción. Bajo este esquema, habitar a un lado de la frontera implica ser natural, respetable o estimable y normal, esto es, implica estar dentro de la normatividad, siendo lo que está en el otro polo lo antinatural. 
Sin embargo, no se puede dejar de recordar que existen casos fronterizos, casos que no encajan en esta conceptualización dual de la realidad, que no son ni A ni no-A, bien por compartir características de ambos lados de la frontera, bien por estar más allá de estos pares, bien por ser graduales, bien por ser más complejos de lo que este esquema permite. Por lo tanto, no será descabellado sospechar que algo falla en los cimientos de las fronteras biológicas.

\section{2. ¿POR QUÉ CREAMOS FRONTERAS BIOLÓGICAS?}

Ante todo aquello que es creado y que, por tanto, podría no haber sido, cabe preguntarse por su razón de ser. Una de las muchas explicaciones que se pueden dar al respecto es el hecho de que las fronteras constituyen una fuente de seguridades para el ser humano, seguridades sobre quiénes somos, sobre cómo es el mundo y sobre qué hacer.

Las fronteras biológicas surgen de la necesidad humana de clasificar y sistematizar, afán bajo el que se encuentra un deseo de simplificar. Así, estas fronteras evitan que la complejidad de lo real haga tambalear nuestras seguridades al mismo tiempo que nos protegen ante lo desconocido, ante todo aquello que hemos decidido - por alguna razón- colocar más allá de la frontera. En efecto, son límites de lo "normal" que nos evitan una vida llena de ansiedades y nos permiten actuar superando un posible estado de incertidumbre o duda constante, el cual llevaría a la inacción plasmada en la imagen del famoso asno de Buridán. ¿Acaso no estarían nuestras vidas teñidas de cierta angustia o, al menos, inseguridad si no contáramos con una frontera, tan clara como circunstancial, entre la vida y la muerte, la salud y la enfermedad, lo normal y lo marginal, el niño y el adulto, el animal y el ser humano, entre la nada y la existencia, entre lo respetable y lo indiferente?, ¿cómo podríamos actuar sin partir de unos supuestos? Es más, ¿acaso actuaríamos o estaríamos más bien avocados a la apatía? ¿Qué haríamos ante los casos complejos y graduales?, ¿cómo trataríamos a los demás?... Piénsese solo en lo angustioso que sería para cualquiera tener que vivir sin alguno de estos supuestos.

Una posible razón que justifica la necesidad de estas fronteras y seguridades no es otra que el miedo a lo desconocido y a lo distinto. Si necesitamos seguridades, implica que existen miedos, incertidumbres, etc.; por lo que las fronteras biológicas remiten, al menos, a una emoción.

En efecto, las fronteras biológicas y los argumentos de pendiente resbaladiza que se utilizan cuando la frontera parece quebrarse remiten a muy diversos miedos, a saber, al miedo a lo desconocido, a lo distinto, a lo extraño, a lo antinatural y a llegar a situaciones o contextos que hemos etiquetado de tal modo.
Si hemos construido lo que somos respecto de lo que no somos, ver que el límite no es tan claro o que se puede traspasar, implica ponernos a nosotros mismos en duda. Sin estas seguridades nos sentimos vulnerables, pues el miedo no es sino una señal que informa de no estar preparados para afrontar una amenaza, sea esta real o no.

Se trata, por tanto, de un miedo en muchos casos a vernos igualados a todos aquellos individuos o situaciones que hemos rechazado. Se trata del miedo a una pérdida de la identidad, a perdernos a nosotros mismos al perder aquellos límites que nos definían, como en el caso de las fronteras étnicas, sexuales y de especie.

Así, el miedo a lo nuevo entendido como miedo a lo/s extraño/s explica que hayamos construido fronteras biológicas unidas a juicios morales en las que se deja fuera todo lo distinto. En segundo lugar, el miedo a todo lo que representa una amenaza para la supervivencia explicaría las fronteras de especie y del final de la vida, pues son peligros evolutivos especiales. Como afirma J. Gray,

"Cuando una situación determinada es con frecuencia responsable de la muerte de una parte considerable de los miembros de una especie, durante un periodo de tiempo lo suficientemente largo (a escala evolutiva), cabe esperar que los individuos de dicha especie desarrollen un temor innato hacia alguno de los estímulos característicos de tal situación, con el fin de evitarla" (Gray, 1993, 32).

Esto explicaría, en parte, por qué no es tan fácil desdibujar las fronteras relativas a la consideración moral de los seres de otras especies, o la frontera entre vivo y muerto en relación con el miedo a los cadáveres.

Del mismo modo, este miedo a que lo nuevo sea un peligro para la supervivencia queda patente en los argumentos a favor de estas fronteras, pues tirar tal barrera sería un hecho novedoso, un cambio que nos dejaría conceptualmente desnudos. Parece claro, entonces, que lo que estos argumentos intenta decir a gritos es que "lo que excede a la capacidad de previsión aparece también como un peligro" (Marina y López Penas, 1999, 245).

Por lo tanto, bajo un supuesto principio de prudencia, se ocultaría un miedo a lo inesperado, a lo distinto, a lo desconocido, a lo extraño y al error humano, lo que demuestra: 1) lo peligroso que es hacer depender de las fronteras biológicas nuestro trato con los demás y nuestros juicios morales, pues nos deja en una minoría de edad constante, y 2) la creciente desconfianza moral hacia nuestros propias capacidades y decisiones cuando no contamos con el respaldo de una fuente externa, entrelazándose así un miedo a renunciar a creencias profundamente arraigadas y 
plasmadas en nuestra cosmovisión dualista con un miedo a que una moral autónoma tenga unas bases poco sólidas.

Así las cosas, se podría aventurar que necesitamos seguridades para vivir y hoy las buscamos en la ciencia y en las interpretaciones que hacemos de ella. Como afirma Warnock, "cuanto más secular se hace una sociedad, más necesarias para su seguridad se hacen las regularidades del mundo natural" (Warnock, 2004, 93). De este modo, si se entienden las fronteras como derivaciones de interpretaciones de la biología, se entiende que la ciencia sea tratada como una nueva fuente de normatividad, "como algo sagrado" (Bloor, 2003, 90).

\section{DE LAS FRONTERAS BIOLÓGICAS A LOS JUICIOS MORALES}

De lo dicho hasta el momento se puede concluir que, en tanto que las fronteras ofrecen seguridades, son útiles. Así, se podría defender que las fronteras biológicas, ficticias o reales, construidas o naturales, se podrían justificar en tanto que son ventajosas vital, psíquica y epistemológicamente. Esto es, existiría una justificación funcional de las mismas.

Sin embargo, nada de esto aporta ninguna pista relevante sobre la in/justificación de derivar juicios morales de ellas. Es decir, afirmar que funcionan porque apaciguan los miedos y aportan seguridades, no es afirmar que sean una fuente legítima, por sí mismas, de juicios y prescripciones morales; pues que sean útiles no implica que sean moralmente relevantes, siendo este salto el verdaderamente peligroso.

De este modo, se podría justificar funcionalmente la existencia de fronteras contingentes, sabiendo que son provisionales y que el avance en los conocimientos las hará móviles, pero no se podrá justificar moralmente su papel como fuente de normatividad. De hecho, el intento implica ya un salto cuestionable al otorgar autoridad moral a un constructo epistémico. Al realizar este salto, se está suponiendo que la existencia y utilidad de algo es suficiente justificación como para convertirlo en coordenada o criterio moral, confundiendo así la realidad ("A es") con la funcionalidad ("A es útil") y con la moralidad ("A es bueno").

Sin embargo, "A es útil" es una proposición fáctica y, por ende, amoral por sí misma, de igual naturaleza que otras proposiciones fácticas como "A existe", "A es natural" o "A es verdad." Todas pertenecen a la esfera del ser, la cual no es identificable con la esfera del deber ser ni con las proposiciones prescriptivas, pues los criterios de veracidad y falsedad no son en ningún caso análogos al criterio de bondad y maldad ni son, en último término, fuente de moralidad. Ciertamente, algunas de las fronteras biológicas creadas pueden ser una quimera, pero ninguna, veraz o no, es moralmente buena o mala en sí misma.

El problema es, pues, que al marcar una frontera de valor hayamos tenido que crear o buscar una frontera ontológica/biológica y viceversa, que al crear o encontrar una frontera de hecho hayamos considerado que también era una frontera de valor.

Sin embargo, si se separan ambos campos, el epistémico y el moral, se ve que la interpretación de las fronteras biológicas, no solo como límites de lo normal, de lo conocido o de lo seguro, sino como límites, garantes y generadoras de lo bueno, nos han puesto ante encrucijadas morales. Hemos identificado la frontera con el límite del bien y lo conocido con lo bueno, aún siendo la funcionalidad irrelevante como argumento moral en el caso de la relación entre fronteras biológicas y juicioso morales.

En definitiva, si se otorga relevancia moral a las fronteras biológicas se estará cometiendo el salto del "es" al "deber" que Hume ya denunció:

"En todo sistema moral de que haya tenido noticia (...) de pronto me encuentro con la sorpresa de que, en vez de las cópulas habituales de las proposiciones: es y no es, no veo ninguna proposición que no esté conectada con un debe y no debe. (...) En efecto, en cuanto que este debe o no debe expresa alguna nueva relación o afirmación, es necesario que esta sea observada y explicada y que al mismo tiempo se dé razón de algo que parece absolutamente inconcebible, a saber: cómo es posible que esta nueva relación se deduzca de otras totalmente diferentes" (Hume, 2005, 633-634).

Así, Hume denunciaría lo que ha dado en llamarse falacia naturalista. Sin embargo, por su relevancia para el asunto de las fronteras biológicas y juicios morales, no querría quedarme únicamente con la interpretación clásica de la injustificación del paso del "ser" al "deber ser". Por el contrario, me gustaría incorporar los matices que pueden aportar dos reinterpretaciones para el caso de las fronteras biológicas, a saber:

1) La reinterpretación como bicondicional. La falacia naturalista se ha leído habitualmente como un condicional -el ser implica el deber ser- en el que es erróneo derivar la conclusión de la premisa. Sin embargo, y si se admite que este salto es falaz, debería leerse también en la otra dirección y denunciar que es igualmente erróneo intentar encontrar un origen natural, ontológico o biológico a todo aquello que se considera bueno, correcto o moralmente prescriptible. Ambos casos se dan en la relación entre fronteras biológicas y juicios morales: intentamos que nuestros juicios morales encajen en las fronteras admitidas, (por ejemplo, que ningún ser humano quede desprotegido aunque no encaje en la definición de persona) 
y derivamos de aquéllas derechos, prerrogativas, etc. En palabras de Pinker, "la falacia naturalista lleva de inmediato a su opuesta, la falacia moralista: si un rasgo es moral, se ha de encontrar en la naturaleza. Es decir, el "es" no solo implica el "deber ser", sino que el "deber ser" implica el "es"”" (Pinker, 2003, 245). En definitiva, se trata de defender, con E. Guisán, que,

"no existe nada menos filosófico que mantener que la virtud es igual a lo natural y el vicio a lo no natural, ya que si entendemos por natural lo que se opone al mundo de la magia y los milagros, tanto el vicio como la virtud son igualmente naturales; si, por otra parte, entendemos natural como lo opuesto a lo no habitual, posiblemente la virtud sea una de las cosas menos habituales o más inusuales, y por último, si natural se opone a aquello que se crea mediante artificio, tanto la virtud como el vicio son creaciones humanas"(Guisán, 1986, 186).

2) La reinterpretación empirista. Es necesario, en lo relativo al método y los presupuestos, recoger la interpretación neonaturalista que se puede hacer de Hume, pues esta muestra que lo que se critica es "cierto tipo de naturalismo, en especial el metafísico y el teológico, pero no toda forma de naturalismo" (Tasset, 1999, 103). Así, se podría ser empirista en la aplicación del método científico -inductivo- al estudio de la moral, sin restar así peso a la ciencia en la labor de comprender qué somos y sin tampoco caer por ello en este tipo de falacia.

Limitar el valor de las fronteras biológicas no implica, o al menos no es la intención de estas páginas, negar cualquier tipo de presencia de la ciencia en el estudio de la moral. Más bien, en la línea de Hume, se pretende reinterpretar el naturalismo, no como base de una moral heterónoma, sino afirmando simplemente que la fundamentación de la moral necesita unos cimientos empíricos, los cuales no deben confundirse con las fronteras dicotómicas anteriormente criticadas. Como señala J. Turner, "somos homínidos en nuestro corazón (...) [y] no podemos, por tanto, desarrollar teorías (...) sin tomar en consideración el legado biológico de nuestros ancestros en tanto que continúa influyendo en la acción y la interacción humana"(Turner, 2000, 1). En pocas palabras, de la ciencia no se pueden derivar juicios morales, sino conocimiento sobre la moral.

Por todo lo dicho habría que cuestionar la tendencia a identificar lo conocido, lo útil y lo bueno, más que las mismas fronteras, pues lo peligroso no son ellas, sino las interpretaciones que se pueden hacer de las mismas. Los problemas morales, las discriminaciones y los abusos relacionados con estas fronteras, no los crean ni los solventas ellas, simplemente los hacen visibles. En este sentido, del mismo modo que no es justificable derivar juicios morales de la simple funcionalidad de algo, tampoco sería necesario cerrar los ojos ante la naturaleza ni eliminar todas nuestras clasificaciones, pues "reconocer la falacia naturalista solo implica que los descubrimientos sobre la naturaleza humana, por sí mismos, no dictan nuestras decisiones" (Pinker, 2003, 248).

\section{EMOCIONES BAJO LAS FRONTERAS}

Derivamos juicios morales de fronteras biológicas y construimos dichas fronteras motivados, entre otras cosas, por emociones tales como el miedo. De esto se podría inferir que la incorrección de derivar juicios morales de estas fronteras se debe a las emociones, siendo estas el origen de toda esta maraña, de las valoraciones y de las consiguientes discriminaciones y abusos surgidos de estas clasificaciones biológicas.

Sin embargo, algo falla en esta argumentación, pues, ¿cómo es posible que aquellos juicios, valoraciones y, en muchos casos, discriminaciones que primero se justificaban como correctos lógica y normativamente, como conclusiones de argumentos racionales sustentados en verdades biológicas u ontológicas, pasen a ser fruto de nuestras emociones cuando ya no creemos en ellos? ¿Cómo es posible que afirmemos de un mismo juicio que está sustentado en la razón cuando nos convence y pase a estar fundado en las emociones cuando descubrimos que hay algo erróneo en él?

Es cierto que tras las fronteras se encuentran emociones pero, ¿son acaso ellas responsables de los juicios morales discriminatorios que hemos derivado de dichas fronteras?

Mi respuesta es negativa. Las emociones no son las responsables - o al menos no únicamente ellas - de los resultados no queridos derivados de las fronteras biológicas, por dos razones, que a continuación desarrollaré:

1- porque estas afirmaciones o acusaciones asumen a su vez la existencia de otra frontera hoy cuestionable, a saber, la establecida entre razón y emoción; y

2- porque no tienen en cuenta el valor cognitivo de las emociones.

\subsection{La frontera entre razón y emoción}

La idea de que las emociones son juicios errados, prejuicios o turbaciones de la razón no es nueva. Tradicionalmente, al menos en occidente, las emociones han sido tratadas como reacciones pasivas, instintos o ideas falsa, contrarias a la razón, en un sentido lógico y normativo. Esto ha tenido varias implicaciones: 1) la conceptualización de las emociones "a expensas de la razón" (Casacubierta, 2000, 9), 2) la constante confu- 
sión o identificación de lo emocional con lo supuestamente bajo, desechable, negativo o devaluado, y 3) la idea, en relación con la moral, de que las emociones son la causa de los comportamientos y acciones irracionales, que en este contexto se traduce en moralmente reprobables.

Ejemplos de lo dicho se encuentran en definiciones de las emociones como "enfermedades del alma" (Lactancio, 1996, 132), "deformaciones de la razón y juicios errados de la misma" (Temistio, 1996,130), "impulsos ciegos y violentos" (Séneca, 1986, 75) o "pensamientos confusos" (Descartes, 1951, 232), así como en consejos tales como "seguir las razones que sean contrarias a las que la pasión presenta" (Descartes, 1972, 133). Por tanto, considero que no es nada aventurado afirmar que el menosprecio de las emociones en el campo cognitivo y moral ha sido la tónica imperante en la filosofía occidental, al menos en el pasado.

En efecto, la tradición filosófica occidental ha supuesto y asumido como algo dado, primero, un dualismo excluyente, un antagonismo irreconciliable entre el par razón-emoción, siendo la emoción lo no racional y viceversa, y, segundo, ha identificado la corrección lógica, y con ella la racionalidad, con la corrección moral. A su vez, el dualismo excluyente que este modelo clásico implica necesariamente escoger uno de los dos polos que conforman el par, lo que, unido a los supuestos asociados a la razón, "lleva normalmente a la gente sensata a rechazar la emoción y a verla como una categoría inapropiada" (Barbalet, 2002, 1).

Partiendo de esto supuestos es comprensible que las emociones hayan sido vistas como una especie de enemigo interior a combatir, como un intruso que no deja pensar, ver y decidir con claridad, o, en definitiva, como aquel elemento ciego, farragoso o turbulento de la psiche humana. Por ello mismo es también comprensible que en la relación entre fronteras biológicas, juicios morales y emociones se haya pensado que estas últimas a) son las causantes de nuestros juicios erróneos y b) no tienen nada que decir respecto de la moral, pues no son sino un obstáculo que coartaría la capacidad de decisión libre al cegarnos y acabarían con el requisito de universalidad de los juicios morales. En palabras de Hume, "nada es más corriente en la filosofía, e incluso en la vida cotidiana, que el que, al hablar del combate entre pasión y razón, se otorgue ventaja a esta última, afirmando que los hombres son virtuosos únicamente en cuanto que se conforman a los dictados de la razón"(Hume, 2006, 558).

Sin embargo, si vamos más allá de la concepción clásica en la que razón y emoción se relacionan como eternos enemigos, se pueden encontrar conexiones relevantes entre estos elementos, de manera que quizás habría que reconsiderar nuestra imagen del ser humano como un individuo esquizofrénico. Siguiendo la idea de Prinz, "preguntar cómo se relaciona la una con la otra puede llevarnos a descubrimientos que no haríamos si no hubiésemos formulado la pregunta" (Prinz, 2004, p.41). De hecho, formular esta cuestión puede llevarnos, en un primer acercamiento, a ver que los límites y las fronteras entre razón y emoción no son tan nítidos. De hecho ninguna definición dada comúnmente sobre la razón agota todo el sentido de este término en todos los casos: o bien incluyen demasiado, o bien demasiado poco.

Así, si se entiende razón, en relación con la funcionalidad y la coherencia, como la capacidad de adecuar medios a fines, como la capacidad de calcular, entonces nos encontramos con que las emociones también son funcionales y también adecuan medios a fines, pues ¿qué hay más racional, funcional o lógico que reaccionar huyendo, en el caso del miedo, cuando algo es valorado/percibido como una amenaza para los fines del sujeto? De hecho, cuanto más complejo es el asunto al que nos enfrentamos, cuanto más compleja es la decisión a tomar, menos racional se vuelve el proceso. Piénsese en que diferente es el proceso de decisión implicado en la acción de echarse a un lado para evitar chocar con un objeto, por ejemplo, y el proceso propio de cualquier dilema moral, interpersonal, etc.

$\mathrm{Si}$, por otro lado, se entiende la razón relacionada como la capacidad de pensar, entonces no hay que olvidar que también pensamos emociones; si la entendemos como un proceso mental, las emociones también son proceso mentales, si entendemos la razón como un proceso mental consciente, entonces habría que señalar, primero, que la razón también se compone de proceso inconscientes, y segundo, que no todo lo consciente es identificable con la razón, así como también que podemos ser conscientes de nuestras emociones. Si, por último, entendemos la razón como universal, habría que señalar que las emociones también son universales, pues al menos en un sentido estructural y más allá de los contenidos, aplicaciones y diferencias culturales y contextuales, todo ser humano está dotado de racionalidad y emocionalidad en un mismo sentido. De manera, que, a primera vista, parece que la frontera entre razón y emoción es no solo erosionable, sino quizás también revisable.

Efectivamente, en primer lugar, más allá del modelo dicotómico, se puede encontrar una relación inclusiva desde una perspectiva evolutiva o temporal entre "cognición" y "emoción" o, si se quiere, entre el cerebro racional y el emocional, pues no se puede pasar por alto el hecho y las implicaciones de que "el cerebro emocional (sea) muy anterior al racional, [siendo este] una derivación de aquel" (LeDoux, 1999, 45). 
Ambos repiten el modelo de muñeca rusa, en el que cada nuevo paso supera e incluye al anterior como fase previa necesaria para su aparición. Este tipo de relación de muñeca rusa entre ambos sistemas vendría, pues, a sintetizar dos máximas de la evolución, a saber, que 1) "la evolución rara vez desperdicia cosas" (De Waal, $2007,46)$ y 2) que "lo viejo siempre está presente en lo nuevo" (De Waal, 2007, 48). Así, del mismo modo que la parte está en el todo, el sistema emocional está implicado ya en el racional o, si se prefiere, "los ordenes inferiores de nuestro organismo están en el bucle de la razón elevada" (Damasio, 2006, 11).

Por otro lado, la frontera entre razón y emoción es también horadable en un sentido funcional. Si se entiende emoción y cognición como procesos mentales, y no ya en un sentido neurológico, entonces emoción y cognición serían más bien un constructo teórico (Ekman y Davidson, 1994) donde las fronteras reales son posiblemente borrosas o graduales. Es decir, si se entiende la cognición como el procesamiento de información, entonces las emociones también son en algún sentido cogniciones pues implican un procesamiento, consciente o inconsciente, de información.

En un sentido más estricto, si se entiende por cognición aquellos procesos con base en el neocórtex o el hipocampo, se podría entender la emoción y la cognición como dos maneras de procesar información bien diferenciadas, identificando la primera con una forma de valorar con efectos directos en la conducta, y la segunda con una razón más elevada.

Sin embargo, en ambos casos, "deberíamos recordar que la mente [y no el cerebro] humana no conoce ninguna línea divisoria entre el pensamiento y el sentimiento" (De Waal, 1997, 105), pues incluso en el segundo caso, la emoción necesitaría de unas bases cognitivas mínimas para poder procesar la información sensorial que encierra, independientemente de que el sujeto sea o no consciente de que tiene emociones o de que estas implican información Al mismo tiempo que la emoción tendría un papel en relación a ala razón en tanto que centra la atención en aquello que es valorado como relevante por y para el sujeto, motiva el razonamiento y ayuda a poner en perspectiva esa amalgama de información percibida.

Por otro lado, la razón también afecta o influye de algún modo en el sistema emocional, pues "una vez que los procesos superiores de ordenación existen, modifican los procesos de la base" (De Waal, 2007, 49).

Por lo tanto, no es aventurado sostener la hipótesis de la interacción, de un bucle de lo emocional a lo racional y de lo racional a lo emocional, en definitiva, de una retroalimentación entre ambas dimensiones, la cual debería afectar y modificar la concepción de un sujeto moral compartimentalizado.
De hecho, un modelo relacional, no dicotómico, explicaría que en algunos casos los procesos cognitivos y los emocionales lleven a una misma solución. Pues "según la psicología evolucionista, la selección natural "diseñó" las emociones humanas para servir a los intereses estratégicos de los individuos de la especie humana" (Wright, 2007, 119).

Asimismo, el sistema emocional interactuaría con el racional y, en concreto, en una faceta de este, a saber, la deliberación -moral o no- y la toma de decisiones. Así, los últimos estudios en neurociencia avalan la hipótesis de que el sistema emocional interviene en la deliberación tradicionalmente entendida como exclusivamente racional.

Pero esto no queda aquí, pues no solo se está afirmando que intervenga o tenga cierta influencia en la toma de decisiones, sino que dicha intervención es inherente al propio proceso deliberativo. De hecho, como De Waal afirma, "las emociones favorecen el razonamiento humano. Los neurocientíficos han descubierto que, por mucho que las personas razonen y reflexionen, si no hay emociones implicadas en las diferentes opciones de que disponen, nunca se alcanza una decisión" (De Waal, 2007,43). Esto modificaría la perspectiva tradicionalmente asumida sobre la racionalidad y el sistema emocional, pues esta influencia no significaría una intervención inevitable en un sentido negativo como un defecto de la racionalidad, sino como un elemento necesario del proceso mismo.

Esta idea se hace patentemente cuando estos científicos señalan qué pasaría en los casos en los que el razonamiento fuera "puro", esto es, estuviera exento de esta influencia emocional, bien por un déficit de la misma, bien por una eliminación hipotética de dicha dimensión:

"en la concepción de la razón elevada, uno separa los distintos supuestos y (...) efectúa un análisis de costes/beneficios de cada una de ellas. (...) Ahora bien, (...) si dicha estrategia es la única de la que disponemos, la racionalidad, como se ha descrito antes, no funcionaría (...) en el mejor de los casos, nuestra decisión tomará un tiempo excesivamente largo, mucho más de lo que sería aceptable si aquel día hemos de hacer alguna otra cosa. En el peor de los casos, puede que incluso no acabemos tomando una decisión, porque nos habremos perdido en los desvíos de nuestro cálculo" (Damasio, 2006, 202-203).

En suma, lo que se sugiere con esto es que quizás sea más conveniente partir de una concepción no antitética del sistema emocional y el racional, pues entre ambos sistemas parece darse una relación de ida y vuelta, a saber, de la emoción a la razón y de la razón a la emoción. Como señala LeDoux, "en este 
momento de nuestra historia evolutiva las conexiones que comunican los mecanismos emocionales con los cognitivos son más fuertes que las que comunican los mecanismos cognitivos con los emocionales" (LeDoux, 1999, 21-22).

Así, si se admite cierta interacción entre razón y emoción, carecería de sentido culpar solo a las emociones de las consecuencias negativas de la construcción de fronteras mientras felicitamos a la razón por lo positivo o funcional que en ellas encontramos, pues también para simplificar, seleccionar información y decidir cuál es valorada como relevante para el sujeto se necesita disponer de un sistema valorativo, a saber, las emociones.

\subsection{El valor cognitivo de las emociones}

Descubrir que las fronteras biológicas nos pueden llevar a abusos y discriminaciones, por un lado, y descubrir que aquellas fronteras están construidas sobre una base emocional podría llevarnos a pensar que las emociones son un error de fábrica, incluso más allá de los límites de la especie.

Sin embargo, desde las teorías evolucionistas, parece que no tendría mucho sentido hablar de errores de fábrica, pues si las emociones fueran una especie de falla, la evolución no habría perpetuado esta dimensión, de manera que, de nuevo, quizás no sea un elemento tan disfuncional como en principio parecería. Por el contrario, parece más adecuado modificar nuestra óptica sobre las mismas.

En este sentido, las emociones pueden definirse como "mecanismos cerebrales programados por la evolución" (LeDoux, 1999, 414), como respuestas neuronales a estímulos relevantes, que implican 1) una evaluación de la situación inicial, del objeto y de sus consecuencias para la supervivencia y bienestar del sujeto, 2) una modificación psicosomática del sujeto y 3) una reorientación de la acción, según el repertorio específico de cada emoción. Esto es, una emoción sería un proceso psicosomático universal ${ }^{1}$ consistente en una respuesta o reacción neuronal espontánea, ${ }^{2}$ de corta duración, a un estímulo que implica un estado mental-afectivo en el que se evalúa la situación inicial respecto del sujeto, sobre el sujeto y para el sujeto que la experimenta. Son, por tanto, respuestas funcionales que permiten la adaptación inteligente - pues adecuan unos medios para llegar a unos fines-, y "nos preparan para tratar con los acontecimientos más importantes de nuestra vida, con o sin haber pensado qué hacer" (Ekman, 2004, 120). En pocas palabras, como bien afirma R. Levenson, "las emociones representan modos de adaptación a las demandas cambiantes del entorno (...), sirven para establecer nuestra posición vis-a-vis con nuestro contexto (Levenson, 1994, 123).
De lo dicho se desprende, y esto es lo relevante respeto del origen de las fronteras biológicas, que toda emoción, incluida el miedo o el asco, remite a una causa, un objeto cuya presencia desencadena esa reacción, y un origen, a saber, una valoración (consciente o inconsciente) de ese objeto como posible amenaza para nuestro bienestar. De este modo, el miedo, al igual que el resto de emociones, tendría una función informadora, de alarma, en este caso del desajuste entre la amenaza y nuestra capacidad para responder a aquella. Esto a su vez implica que detrás de cada emoción subyace 1) una creencia o valoración, a saber, "X es peligroso," y 2) un deseo, normalmente la supervivencia y el bienestar. Como afirma Damasio, "incluso cuando la reacción emocional tiene lugar sin conocimiento consciente del estímulo emocionalmente competente, la emoción significa no obstante el resultado de la evaluación de la situación por parte del organismo" (Damasio, 2005, 56).

Por tanto, y aunque las fronteras biológicas remitan a emociones, no son estas su origen, sino las valoraciones que se han hecho previamente de la realidad y han llevado a considerar, por ejemplo, X como peligroso o como una amenaza, pues es esta creencia asociada al objeto la que desencadenará la emoción del miedo. Como afirma M. Nussbaum, "las emociones representan no solo maneras de ver un objeto, sino creencias - a menudo muy complejas - sobre el objeto" (Nussbaum, 2006, 28).

Así, aunque bajo las fronteras subyazcan emociones, el problema no son estas, pues toda emoción remite a una causa, sino más bien una mala aplicación de la emoción a un contexto dado. En efecto, esta mala aplicación se debe a una creencia incorrecta o inexacta respeto de la situación, fruto de una inadecuada valoración de esa circunstancia. Dicho de otro modo, las emociones no son más que herramientas cuyo éxito, fracaso o conveniencia depende en parte de la utilización que el sujeto haga de ellas, del contexto al que se aplique y de la herramienta concreta -la emoción- que se desencadene, según las creencias previas.

Así, desencadenar una reacción de alegría ante un francotirador no muestra la disfuncionalidad de las emociones, sino el desconocimiento por parte de ese sujeto del poder letal de las balas o el deseo del mismo de no seguir viviendo. Del mismo modo, cuando ante casos fronterizos desencadenamos una reacción de miedo o asco, habrá que cuestionarse qué creencia o valoración de los mismos subyace en aquella emoción. Por lo tanto, en el caso de las fronteras biológicas y los juicios morales, cabría afirmar que lo incorrecto o lo cuestionable no es sentir miedo o asco, por ejemplo, ante lo distinto, sino creer que lo distinto es en sí mismo una amenaza y derivar unas prerrogativas 
de dicha idea. Como bien afirma Hume, "una pasión deberá ser acompañada de algún falso juicio para ser irrazonable; e incluso, para hablar con propiedad, no es la pasión lo irrazonable, sino el juicio" (Hume, 2005, 563).

En efecto, de esto no se deduce que las emociones sean disfuncionales, ${ }^{3}$ sino más bien que pueden ayudar a caer en la cuenta, a modo de alarmas, de que algunas creencias y presupuestos son cuestionables y revisables. En palabras de R. Joyce, "todos tenemos la capacidad de tener miedo, pero qué temer (...) es algo que aprendemos de nuestro entorno, el cual incluye especialmente, lo que aprendemos de otros humanos" (Joyce, 2006, 7).

\section{CONCLUSIÓN}

De lo dicho se deriva, para concluir, que 1) quizás sería necesario una ampliación o un cambio en el concepto clásico de racionalidad de manera que tuviera cabida la idea aquí señalada, a saber, "que, en lugar de ser la antítesis de la racionalidad, las emociones favorecen el razonamiento humano" (De Waal, 2007, 43); y 2) que la racionalidad necesita de lo emocional, de manera que ni la razón es tan fría, ni la emoción es tan irracional como podría pensarse.

En consecuencia, lo relevante aquí es señalar que la creencia de que los juicios morales "incorrectos" en algún sentido son fruto de la emoción y los "correctos" de la razón deja de tener sentido, pues razón y emoción van de la mano y son ambas condición necesaria de cualquier juicio moral.
Así, tan pronto como reconsideremos 1) el marco conceptual en el que se asientan nuestras clasificaciones, 2) el dualismo excluyente y 3 ) el intelectualismo moral derivado de la tensión y la jerarquización del par razón/emoción, los problemas derivados de un paradigma dicotómico, tales como la discriminación, la instrumentalización y homogeneización de lo considerado inferior, podrían atenuarse.

En efecto, vernos no como animales esquizofrénicos, sino como seres formados por una red de dimensiones interconectadas ayudaría a comprender las emociones como un elemento integrado en nuestra naturaleza, a entender que la aparente responsabilidad única de las emociones ante las discriminaciones derivadas de las fronteras viene de la tendencia propia del intelectualismo moral de identificar condiciones de posibilidad (razón) con criterios de normatividad (racionalidad). Del mismo modo, una relación no dicotómica entre razón y emoción nos ayudaría a ver que la frialdad emocional puede llevar a la frialdad moral, y con ella, a la indiferencia ante los posibles daños morales que otro individuo pueda padecer como consecuencia de los juicios morales derivados de las fronteras biológicas.

\section{AGRADECIMIENTOS}

Este trabajo no estaría completo sin mi agradecimiento a aquellos cuya generosidad me ha permitido confeccionar estas páginas: Carmen Velayos, Luciano Espinosa, Antoni Gomila y Peter Goldie.
1 La emoción es propia de todo miembro de la especie en condiciones normales, aunque se exprese de diversas maneras y esté modulada por distintos factores culturales.
2 Téngase en cuenta que incluso cuando se evoca una emoción, mediante el recuerdo, por ejemplo, el deseo de experimentar esa emoción es voluntario, pero la aparición propiamente dicha de esta seguirá siendo espontánea.
3 Al menos, a corto plazo (FernándezBerrocal y Ramos, 2005).

\section{BIBLIOGRAFÍA}

Barbalet, Jack (ed.) (2002). Emotions and Sociology. Oxford: Blackwell.

Bloor, David (2003). Conocimiento e imaginario social. Barcelona: Gedisa.

Casacubierta, David (2000). ¿Qué es una emoción? Barcelona: Crítica.

Charo, R. Alta (1999). "Dusk, dawn and defining death. Legal classifications and biological categories". En Yougner, Stuart J.; Arnold, Robert M. y Schapiro, Reni (eds.), The definition of death. Contemporary controversies. London: John Hopkins University, pp. 277-292.

Damasio, Antonio (2005). En busca de Spinoza. Neurobiología de la emoción y los sentimientos. Barcelona: Drakontos.
Damasio, Antonio (2006). El error de Descartes. La emoción, la razón y el cerebro humano. Barcelona: Drakontos.

Descartes, René (1972). Las pasiones del alma. Barcelona: Península.

Ekman, Paul (2004). "What we become emotional about". En Manstead, Anthony S.R.; Fischer, Agneta H. y Fridja, Nico H., Feeling and emotions. The Ams- 
terdam symposium. Cambridge: Cambridge University Press, pp. 119-135.

Ekman, Paul y Davidson, Richard J. (eds.) (2004). The Nature of emotion. Fundamental questions. Oxford: Oxford University Press.

Fernández-Berrocal, Pablo y Ramos, Natalia (eds.) (2005). Corazones inteligentes. Barcelona: Kairós.

Guisán, Esperanza (1986). Razón y pasión en ética. Los dilemas de la ética contemporánea. Barcelona: Anthropos.

Gray, Jeffrey A. (1993). La psicología del miedo y el estrés. Barcelona: Labor.

Hume, David (2005). Tratado de la naturaleza humana. Madrid: Tecnos.

Hume, David (2006). Investigación sobre los principios de la moral. Madrid: Alianza.

Joyce, Richard (2006). The evolution of morality. U.S.A.: MIT Press.

Lactancio (1996). "Epítome de las instituciones divinas" 33, 6 [S.V.F. I 213]. En VV. AA., Los estoicos antiguos. Madrid: Gredos.

LeDoux, Joseph (1999). El cerebro emocional. Barcelona: Ariel/Planeta.

Levenson, Robert (1994). "Human emotion: a functional view". En Ekman,
Paul y Davidson, Richard J. (eds.), The Nature of emotion. Fundamental ques tions, Oxford: Oxford University Press, pp.123-126.

Marina, José Antonio y López Penas, Marisa (1999). Diccionario de los sentimientos. Barcelona: Anagrama.

Nussbaum, Martha C. (2006). Upheavals of thought. The intelligence of emotions. Cambridge: Cambridge University Press.

Pinker, Steven (2003). La tabla rasa. La negación moderna de la naturaleza humana. Barcelona: Paidós.

Plumwood, Val (1993). Feminism and the mastery of Nature. London: Routledge.

Prinz, Jesse J. (2004). Gut reactions. A perceptual theory of emotions. Oxford/ New York: Oxford University Press.

Prokhovnik, Raia (1999). Rational woman. A feminist critique to dichotomy. London: Routledge.

Séneca, Lucio A. (1986). Diálogos. Madrid: Tecnos.

Shakespeare, William (1999). Hamlet. Madrid: Cátedra.

Tasset, José Luis (1999). La ética y las pasiones. Un estudio de la filosofía moral y política de David Hume. A Coruña: Universidade da Coruña.
Temistio (1996). "Paráfrasis al 'Sobre el alma' de Aristóteles" 90 b II 197, 24 Speng. [S.V.F. I 208]. En VV. AA., Los estoicos antiguos, Madrid: Gredos.

Turner, Jonathan H. (2000). On the origins of human emotions. A sociological enquiry into the evolution of human affect. California: Standford University Press.

De Waal, Franz (1997). Bien natural. Los orígenes del bien y el mal en los humanos y otros animales. Barcelona: Herder.

De Waal, Franz (2007). Primates y filósofos. La evolución de la moral del simio al hombre. Barcelona: Paidós.

Warnock, Mary (2004). Fabricando bebés ¿Existe un derecho a tener hijos? BarceIona: Gedisa.

Warren, Karen J. (1990). "The power and the promise of ecofeminism". Enviromental Ethics, 12 (2), 125-146.

Wright, Robert (2007). "Los usos del antropomorfismo". En de Waal, Franz (ed.), Primates y filósofos. La evolución de la moral del simio al hombre. Barcelona: Paidós, pp. 115-130. 